\title{
Cytotoxicity Effect of Quercus infectoria Based Vaginal Cream on Hela Cells and its Preliminary in Vivo Toxicity Evaluation Towards Female Rats
}

\author{
Hazwani $M Y^{\mathrm{a}}$, Hasmah $\mathrm{A}^{\mathrm{b}^{*}}$, Wan Amir Nizam WA \\ ${ }^{a}$ Biomedicine Programme, School of Health Sciences, Universiti Sains Malaysia, Health Campus, 16150, \\ Kubang Kerian, Malaysia \\ ${ }^{b}$ Environmental and Occupational Health Programme, School of Health Sciences, Universiti Sains Malaysia, \\ Health Campus, 16150, Kubang Kerian, Malaysia
}

\section{ABSTRACT}

Introduction: Cervical cancer is the third leading cause of cancer death among females in less developed countries. Drugs used in the treatment of cervical cancer were reported to exert a cytotoxic effect on the normal cells. This study aimed to determine the effectiveness of Quercus infectoria (QI) vaginal cream towards cervical cancer cell, HeLa and its toxicity effect on the female rat model. Methods: MTT assays were utilized to determine the median concentration $\left(\mathrm{IC}_{50}\right)$ for cell cytotoxicity of QIA and QI vaginal cream against cervical cancer cells, HeLa. Expression of HPV E6 and E7 protein in HeLa cells treated with QI vaginal cream for 24 hours were conducted by Western blot analysis. In separate experiments, the toxicity of QI vaginal cream on a lower reproductive tract of the female rat model has been assessed by histopathological examination after application for three weeks. The antioxidant activity of QIA extract and QI vaginal cream were assessed by DPPH radical scavenging assay. Results: A moderate cytotoxicity activity exerted by QIA extract and QI vaginal cream against HeLa cell with $\mathrm{IC}_{50}$ values of $13.90 \pm 2.27$, and $20.80 \pm 1.94$ respectively. Furthermore, QI vaginal cream suppressed the expression of HPV E6 and E7. Daily application of QI vaginal did not exert any inflammation to the vaginal mucosa and cervix. QIA extract and QI vaginal cream demonstrated high DPPH radical scavenging activity. Conclusion: Formulated QI vaginal cream has cytotoxic effect on HeLa cells without causing an adverse effect on the lower reproductive tract in female rat model.

KEYWORDS: Quercus infectoria gall extract, cream formulation, cell cytotoxicity, toxicity evaluation.

\section{INTRODUCTION}

Cervical cancer is the third leading cause of cancer death among females in less developed countries and estimated about 265,700 deaths worldwide in 2012. ${ }^{1}$ In Malaysia, cervical cancer is the fifth cause of female cancer deaths and estimated about 621 deaths by $2012 .{ }^{2}$ Almost $70 \%$ of its causal factors are by human papillomavirus (HPV) types 16

Corresponding Author:

Assoc. Prof Dr. Hasmah Abdullah

School of Health Sciences

Health Campus Universiti Sains Malaysia

16150 Kubang Kerian, Kelantan

Tel: 097677534 (direct line)

$\mathrm{Hp}: 0179571353$

Email: hasmahab@usm.my and 18 infections $^{3}$ and these types functioned as oncoproteins in the development of cervical cancer. ${ }^{4}$

Chemotherapy drugs are one of the leading approaches for the treatment of cervical cancer. Unfortunately, this treatment is usually associated with cytotoxic effect on the normal dividing cells. ${ }^{5}$ Thus, selective and efficient target of cancer cells is the foremost goal in the development of anticancer therapeutics. ${ }^{6}$ Nowadays, numerous studies have been conducted on the potential of plants for medicinal purposes. Used of plants for therapeutic agents has been developed because of several factors, including efficiency, safety and economic feasibility. ${ }^{7}$ Over time, there are many plants with reported anticancer activities. ${ }^{8,9}$ 
In Malaysia, QI gall is known as Manjakani and had been used for centuries as traditional medicines. The local Malay women commonly utilized QI extract as remedies for postpartum care. ${ }^{10}$ Pharmacological evaluation of $\mathrm{Q}$ I gall has demonstrated various biological effects. ${ }^{11}$ The gall extract was noticeably having antioxidant activity $^{12}$ and this strong antioxidant activity is probably due to the presence of bioactive compounds such as tannin, gallic acid, and ellagic acid. ${ }^{13}$ Previous study suggested an antioxidant activity has contributed to the anticarcinogenic effects, ${ }^{14}$ and able to inhibit cervical cancer cell lines (HeLa) in vitro. ${ }^{15}$

In recent years, the vaginal path has been proven as an effective route for local and systemic delivery of drugs. ${ }^{16}$ This is due to the location of the vagina that allows for easy accessibility. ${ }^{17}$ As compared to oral administration of the drug, the vaginal drug delivery has more advantages with the ability to bypass firstpass liver metabolism, avoidance of gastrointestinal irritation and side effect towards gastrointestinal tract. ${ }^{16}$ Therefore, there are number of vaginal drug delivery systems have been developed in clinical and research setting. Previously, metronidazole and clindamycin vaginal creams were used for the treatment of bacterial vaginosis and proven effective as oral delivery. ${ }^{16}$

To date, the study used plants extract in vaginal cream formulation as alternative treatment for cervical cancer is scarce. Hence, the intravaginal application of nutraceutical-based cream might be a potent and safe alternative with improved efficacy. In the present study, the QI gall extract was used in the formulation of vaginal cream to suppress the growth of cervical cancer cells in vitro without causing any adverse effect on the lower reproductive tract of rat model.

\section{MATERIALS AND METHODS}

\section{Preparation of QI gall extract}

The QI gall was purchased from the local herbal market, Kota Bahru, Kelantan and the gall were extracted according to the previous study. ${ }^{18}$ The extract powder was stored at $-20^{\circ} \mathrm{C}$ until use.

\section{Formulation of Ql vaginal cream}

Oil in water $(\mathrm{O} / \mathrm{W})$ emulsion-based cream was formulated according to the previous study with modifications. ${ }^{19}$ Firstly, the oil soluble components were mixed together, heated and homogenized at $70^{\circ} \mathrm{C}$ (oil phase). For water phase, all water soluble components were mixed, heated and homogenized at $70^{\circ} \mathrm{C}$. After heating, the water phase was added to the oil phase slowly with constant stirring at $70^{\circ} \mathrm{C}$ and once the transfer has completed, the formulation was allowed to cool at room temperature, all the while being stirred. The formulation was shown in Table I.

Table I: Formulation of QI vaginal cream

\begin{tabular}{cc}
\hline Ingredients & Percentage (\%) \\
\hline Cetyl alcohol & $2 \%$ \\
Glycerin & $2 \%$ \\
Mineral oil & $10 \%$ \\
Stearic acid & $7 \%$ \\
Triethanol Amine & $2 \%$ \\
Extract & Up to $5 \%$ \\
Distilled water & Up to $100 \%$ \\
\hline
\end{tabular}

\section{Cell culture}

Human cervical cancer (HeLa) cell lines were purchased from American Type Culture Collection (ATCC, Manassas, Virginia, USA). The cell lines were cultured in complete medium containing Dulbecco's modified Eagle medium (DMEM) (Invitrogen, USA) with $10 \%$ fetal bovine serum (FBS) (Gibco, Life Technology) supplemented and $1 \%$ penicillinstreptomycin (Invitrogen, USA). The cell cultures were incubated in a $5 \% \quad \mathrm{CO}_{2} \quad 37^{\circ} \mathrm{C}$ humidified incubator (Sheldon Lab, USA). All protocols involved with cell cultures were carried out under strict aseptic conditions and was performed in Biosafety Cabinet Class II (Erla Technologies, Malaysia).

\section{Cell treatments}

Prior to treatment, the cells were seeded at $5 \times 10^{4}$ cells $/ \mathrm{ml}$ in 96-well plate and incubated in $5 \% \mathrm{CO}_{2}$ $37^{\circ} \mathrm{C}$ incubator until reaching $80 \%$ confluency. The QIA extract and QI vaginal cream was used for treatment and diluted in dimethyl sulfoxide (DMSO). Cisplatin was used as a positive control, and untreated cells with a complete medium was served as a negative control. The treated and untreated cells were incubated for 72 hours.

\section{MTT assay}

MTT 3-(4,5-dimethyl-2-thiazolyl)-2, 5-diphenyl-2Htetrazolium bromide (Gibco, Life Technology) assay was performed to evaluate cytotoxicity effects of QIA extract and QI vaginal cream against HeLa cell 
lines. In this assay, yellow colour of MTT was reduced to purple formazan product of cellular mitochondrial dehydrogenase enzyme in living cells. $^{20,21}$ The treated and untreated cells were incubated with $100 \mu \mathrm{L}$ culture medium and $20 \mu \mathrm{l}$ MTT solutions for 4 hours in the incubator. Then, the medium with MTT solution was discarded, and replaced with $100 \mu \mathrm{LMSO}$ and incubated for 20-30 minutes. Optical density was read at $570 \mathrm{~nm}$ using an ELISA reader (Bio-Rad Microplate Reader Model $680)$. The $I C_{50}$ value was determined from the dose response curve (\% of cell viability versus final concentrations) by calculating the percentage of cell viability by following formula ${ }^{19}$ and then, the criteria for cytotoxicity were adapted from the guidelines of the National Cancer Institute $(\mathrm{NCl}) .{ }^{22}$

Cells cytotoxicity $=(O D$ value of treated cells $/ O D$ value of untreated cells) $\times 100$

\section{Western blot analysis}

B-actin, Anti-mouse IgG, HPV E6 antibody, and HPV E7 antibody (Santa Cruz Biotechnology) were used in this study. HeLa cell lines were treated with Q vaginal cream by means of $\mathrm{IC}_{50}$ from MTT assay for 24 hours. The expressions of HPV E6 and E7 in treating HeLa cell lines were determined by western blot analysis. The expression both proteins were detected by Enhanced chemiluminescence solution (Merck Millipore) and exposed in chemiluminescence detection. The integrated density value (IDV) was measured by image $J$ software. Then, the mean relative intensity (MRI) for both expressions of proteins was determined by following a formula:

\section{MRI of $=$ IDV target protein (E6 or E7) prontein
expression}

\section{Animals}

Healthy female Sprague-Dawley rats (8-10 weeks old, 200-250 g) were used and procured at Animal Research and Service Centre (ARASC), USM Health Campus, Kelantan. The animals were housed under standard laboratory condition $\left(20 \pm 20^{\circ} \mathrm{C}, 12\right.$ hours light and 12 hours dark cycle) and were fed with standard laboratory chow diet and tap water ad libitum. The protocols for these experiments were approved by the Animal Research Ethics Committee of USM (JEHUSM) with certificate number USM/ Animal Ethic Approval/2015/ (652).

\section{Toxicity test for Ql vaginal cream}

Toxicity test was performed to determine the local toxicity effect of the QI vaginal cream on the lower reproductive tract of the female rat. This study was performed according to previous study with modifications. ${ }^{23}$ In this study, twelve female rats were divided into three groups. Group 1 acted as a control group and received PBS intravaginally. Group 2 acted as treated control group and received base cream intravaginally, and Group 3 acted as treated group and received QI vaginal cream intravaginally. The applications were continued daily for 3 weeks everyday and the application of substances were carried out according to previous study. ${ }^{24}$ After 3 weeks, the cervix and vagina of rats were dissected for histopathology examination. However, in order to minimize variations in inflammation, the rat's vaginal smear was monitored and subsequently each rat was euthanized at the first proestrus stage following the last treatment. ${ }^{23}$

\section{Antioxidant activity}

The antioxidant activity of QI vaginal cream and QIA extract was evaluated by verifying the ability of this sample to scavenge free radicals of 1, 1-diphenyl-2picryl-hydrazyl (DPPH) radical. ${ }^{25}$ Firstly, $0.08 \mathrm{mg} / \mathrm{ml}$ of DPPH, and $1 \mathrm{mg} / \mathrm{ml}$ of QIA extract and QI vaginal cream was prepared with methanol. Then, $2.5 \mathrm{ml}$ of QIA extract and QI vaginal cream was added into 2.5 $\mathrm{ml}$ DPPH and kept in a dark for 30 minutes at room temperature. Decrease in absorption was measured by spectrophotometer at $517 \mathrm{~nm}$. The experiment was done in triplicate and the average was calculated. The radical scavenging activity of the samples was calculated by using the following formula (control $=$ methanol + DPPH, blank $=$ sample + methanol):

$\%$ DPPH radical scavenging activity $=\left[\frac{\text { Abs control }- \text { Abs Sample }}{A b s \text { control }} \times 100\right]$

\section{RESULTS}

\section{Formulation of QI vaginal cream}

In this study, the only formulation of the cream was conducted without any characterization. The characterization of the cream shall be conducted in the future. The appearance of formulating cream was evaluated by its state, colour, odour and oily state. The selection and amount of excipients used was done after several trials. The first trials contained excess oil, which produced a greasy sense on usage and low consistency. Therefore, the 
formula was modified by reducing the oil phase components and replacing it with water phase components. Finally, the best formulation was chosen based on the physical appearance of the cream, which are semisolid form, brownish colour, herb odour and slight oily (Figure 1).

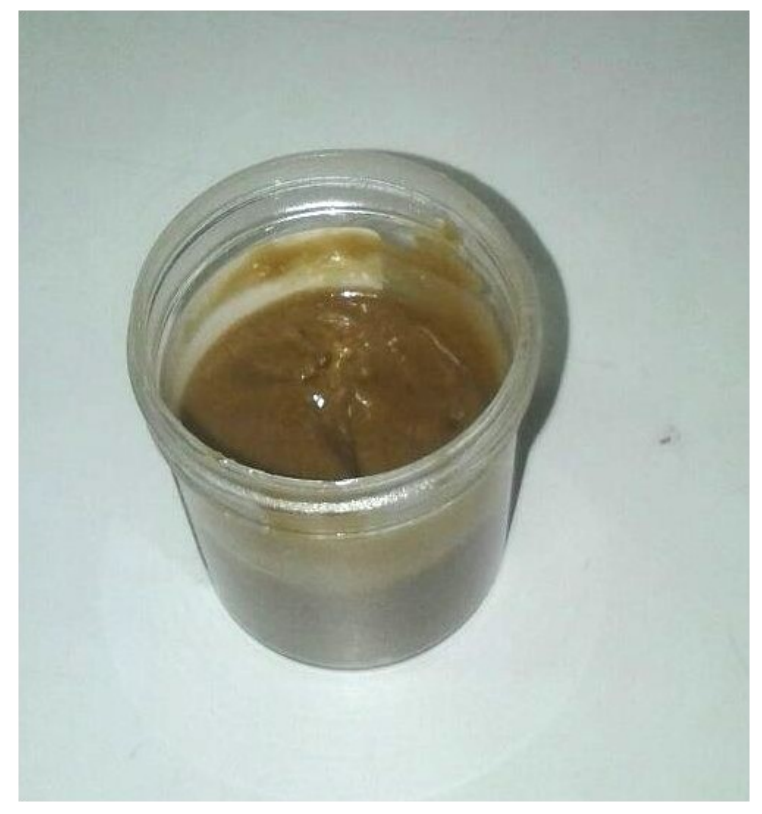

Figure 1: The physical appearance of vaginal cream in semisolid form, brownish colour, herb odour and slight oily

\section{Cytotoxicity effect}

Result showed, IC $\mathrm{C}_{50}$ of QIA extract (representing non -formulated extract) is $13.90 \pm 2.27 \mu \mathrm{g} / \mathrm{ml}$, whereas, IC $C_{50}$ of $\mathrm{Q}$ vaginal cream is $20.80 \pm 1.94 \mu \mathrm{g} / \mathrm{ml}$. Therefore, it is obviously that QIA extract alone showed higher cytotoxic activity, while formulated QI vaginal cream showed greater $\mathrm{IC}_{50}$, but not much difference with QIA extract. Cisplatin act as positive control showed the best $I_{50}, 10.05 \pm 1.98 \mu \mathrm{g} / \mathrm{ml}$. All treated cells showed cytotoxic effects in a concentration dependent manner (Figure 2).

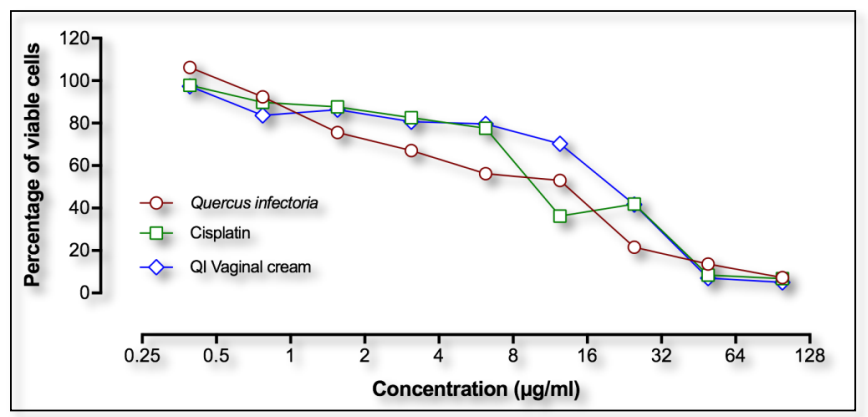

Figure 2: Mean percentage of viable cells showing cytotoxic effect of QIA extract, QI vaginal cream, and Cisplatin on HeLa cell lines after 72 hours.
Expression of HPV E6 and E7 by Western blots

The untreated cells showed gradual expression of HPV E6 and E7 protein with mean relative intensity (MRI) 1.03 and 1.37 respectively, whereas the treated cells showed high suppression of HPV E6 and E7 protein with MRI 0.68 and 0.89 respectively (Figure 3 and 4).

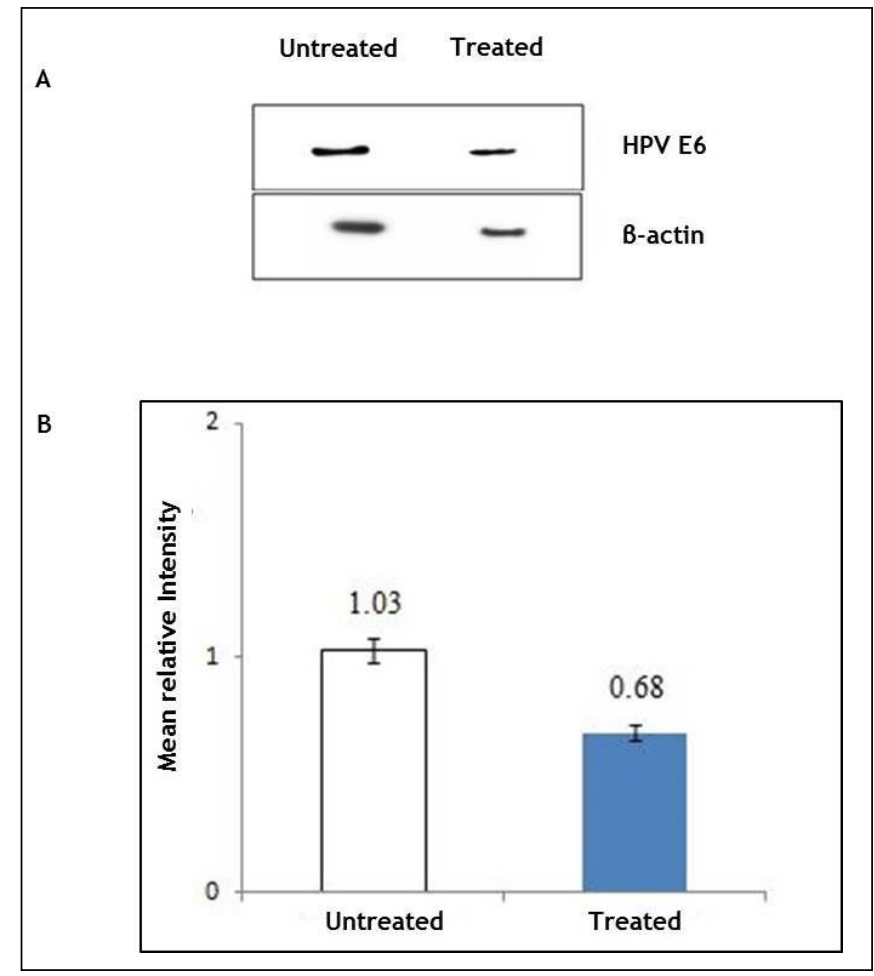

Figure 3: The expression of E6 protein after 24 hour treatments with $\mathrm{Q}$ l vaginal cream $\left(\mathrm{IC}_{50} 20.80 \pm 1.94\right)$ on HeLa cells, A. B-actin served as housekeeping gene to show equal loading. Mean relative intensity of untreated and treated cells, $\mathrm{B}$.

A
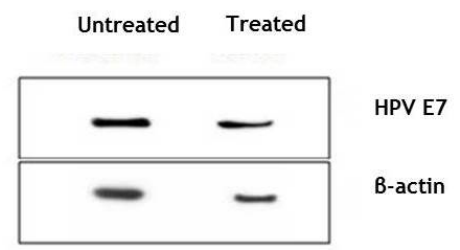

B

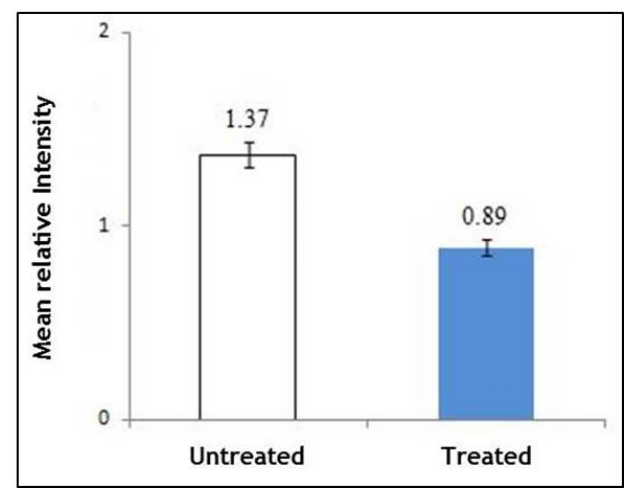

Figure 4: The expression of E7 protein after 24 hour treatments with $Q$ l vaginal cream $\left(I_{50} 20.80 \pm 1.94\right)$ on HeLa cells, A. B-actin served as housekeeping gene to show equal loading. Mean relative intensity of untreated and treated cells, B. 
Histopathological evaluation for toxicity testing of QI vaginal cream

After application, cervix and vagina from QI vaginal cream-treated group did not show any increased signs of inflammation as well as in PBS-untreated control group and base cream-treated control group. Also, all vaginal epithelium of rats did not show any ulceration, areas of necrosis, or micro abscess formation (Figure 5).

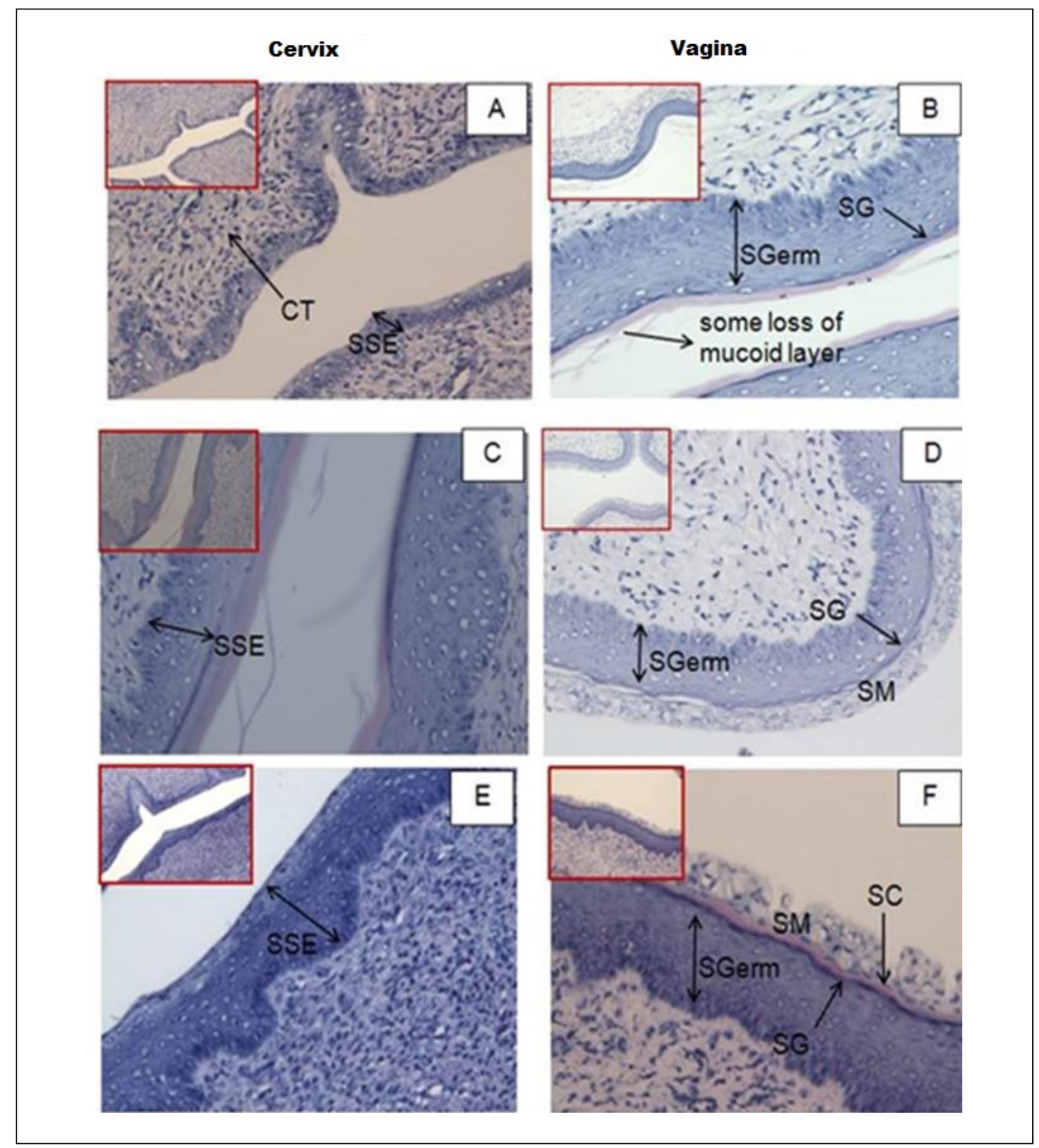

Figure 5: Histopathological examination of cervix and vagina with H\&E staining. The images from each group were shown with high magnification, 20X (large image) and low magnification, 10X (inset) $[A, B=P B S$-untreated control group. $C, D=$ base cream-treated control group. $E, F=Q \mid$ vaginal cream-treated group. Stratum mucification (SM), stratum corneum (SC), stratum granulosum (SG), stratum germinativum (SGerm), squamous epithelium (SSE), connective tissue (CT)]

\section{Antioxidant activity}

Both samples, QIA extract and vaginal cream showed high DPPH radical scavenging activity with more than $90 \%$ radical scavenging (Table 2 ). This indicated that QIA extract and QI vaginal cream contain high antioxidant activity that has potential as anticancer activity.

Table 2: Antioxidant activity of QIA extract and QI vaginal cream

\begin{tabular}{ll}
\hline Sample & DPPH radical scavenging (\%) \\
\hline QIA extract & $98.8 \pm 0.21$ \\
Ql vaginal cream & $94.6 \pm 0.28$ \\
\hline
\end{tabular}




\section{DISCUSSIONS}

The vagina is an interesting site for drug delivery either for local or systemic effects. In the development of new drugs, especially for female patients, various forms of intra-vaginal administration has been developed, including creams, gel, and suppositories. ${ }^{24}$ Therefore, the current study formulated vaginal cream with hope to enhance the drug delivery and in order to obtain a local effect. In this study, the QI gall extract was chosen for the formulation of vaginal cream due to its ability to exhibit the antiproliferative activity of cancer cells and also contain high antioxidant properties. ${ }^{15,25}$

In this study, non-cream formulated extract; aqueous extract (QIA) showed greater cytotoxicity effect against cervical cancer cell, HeLa compared to QIA vaginal cream. Previously, the other types of Q extract and ethanolic extract exhibit more potent cytotoxicity effect compared to aqueous and methanol extract. ${ }^{15}$ However, in another study, which utilised aqueous extract showed a greater cytotoxicity effect towards HeLa cells compared to ethanolic extract. ${ }^{26}$ Obviously, those studies utilised same solvent for extraction, but used different approaches of extraction procedure which play a critical role in the extraction outcome (phytochemicals content, yield and bioactivity). ${ }^{38}$ In the current study, extract in cream formulations exhibit feasible characteristic to inhibit the growth of HeLa cells, even though it was less potent compared to non-formulated extract. Further studies are necessary to elucidate the effectiveness of formulating cream to deliver the drugs to the receptor sites such as a skin permeation assay, evaluation of drug permeation and cutaneous retention study. ${ }^{39}$ The current findings open up the drug delivery option to treat cervical cancer through vagina route.

The positive control, cisplatin showed a wide range of anticancer activity and in combination with other substances has resulted in the improvement of its efficacy in cancer treatments. ${ }^{1,27,28}$ Despite, cisplatin demonstrated the most potent cytotoxicity effect on HeLa cell, but cisplatin also cytotoxic towards normal cell. ${ }^{29}$ Cisplatin also has been reported to have several toxicity effects including neurotoxicity, ototoxicity, nausea and vomiting, and nephrotoxicity. ${ }^{30}$
In the present study, the expression of E6 and E7 viral proteins in HeLa cell lines were highly suppressed when treated with QI vaginal cream. The E6 and E7 viral proteins play important role in the HPV life cycle and over expression of these proteins causes inactivation of p53 and pRb that responsible for regulation of cell cycle and apoptosis. ${ }^{31}$ Previous work also exhibited that QIA extract alone was able to induce apoptosis through p53-dependent pathway. ${ }^{26}$ Compared to different plant compound such as curcumin, effectively suppresses the transforming antigen E6, and then dramatically inhibits the expression of the pro-cancer protein (EGFR) and induces p53. ${ }^{23}$ From these findings, it is suggested that QI vaginal cream is able to suppress the expression of both HPV E6 and E7 protein in HeLa cell lines, and also may block HPV-associated transformation of cervical cancer cells.

In this study, daily application of QI vaginal cream for three weeks did not cause any increase inflammation of the vaginal mucosa and cervix. This finding was compatible with previous study where QIA extract alone did not show any cytotoxic effect in vitro and considered as safe. ${ }^{32}$ Similarly, in vivo toxicity of QIA extract did not show toxicity effect despite receiving the highest dose by oral administration and also did not cause local mucosal irritation. ${ }^{33}$ Therefore, it is suggested that QI vaginal cream was feasible and safe to be used as an alternative treatment to eradicate cervical cancer cell growth.

Recently, a large number of medicinal plants have been found to have antioxidant properties, leading to anticancer activities. ${ }^{34}$ Natural antioxidants that are present in plants are responsible for inhibiting or preventing the deleterious consequences of oxidative stress..$^{35}$ In the present study, the free radical scavenging activity of QIA extract and Q vaginal cream were evaluated by DPPH antioxidant assay. Based on the result, QIA extract and QI vaginal cream showed high antioxidant activity. This finding was compatible with previous study where QIA extract showed high antioxidant activity compared to other solvents. ${ }^{25}$ It has been shown that high antioxidant activity of Ql gall might be due to the presence of gallic acid and tannic acid, which are proven to possess antioxidant activity ${ }^{36}$ and inhibited the superoxide and 1,1-diphenyl-2-picrylhydrazyl (DPPH) radical scavenging activities. ${ }^{37}$ 


\section{CONCLUSION}

In conclusion, development of nutraceutical-based cream namely QI vaginal cream was able to inhibit cervical cancer cells in vitro without any adverse effect on the lower reproductive tract, and its beneficial effects could be exploited as alternative treatment for cervical cancer.

\section{ACKNOWLEDGEMENTS}

This project was fully funded by Universiti Sains Malaysia, Research University Grant Scheme coding 1001 /PPSK/813061.

\section{REFERENCES}

1. Asgar MA, Senawong G, Sripa B, Senawong T. Scopoletin potentiates the anticancer effects of cisplatin against cholangiocarcinoma cell lines. Bangladesh Journal of Pharmacology 2015 Jan 21; 10(1):69-77.

2. Bruni L, Barrionuevo-Rosas L, Albero G, et al. ICO Information Centre on HPV and Cancer (HPV Information Centre). Human papillomavirus and related diseases in India. Summary Report 2015 Mar: 12-23.

3. Puteh SEW, Samsuddin NR, Hussain SNAS, Shah SA, Aljunid SM. HPV Positivity and its' Influencing Factors among Invasive Cervical Cancer Women in Malaysia. International Journal of Public Health Research 2011; 1 (1):13-22.

4. Oh ST, Longworth MS, Laimins LA. Roles of the E6 and E7 Proteins in the Life Cycle of Low-Risk Human Papillomavirus Type 11. Journal of Virology 2004; 78(5): 2620-2626.

5. Fernando J, Jones R. The principles of cancer treatment by chemotherapy. Surgery (Oxford) 2015 Mar 31; 33(3):131-5.

6. Chabner BA, Roberts Jr TG. Chemotherapy and the war on cancer. Nature reviews. Cancer 2005 Jan 1; 5(1):65.

7. Hashim ST, Hamza IS, Hassan MA. Identification of Quantative Chemical Compounds of Ethanolic Extracts of Quercus Infectoria and Studies its Inhibitory Effect in Some Bacteria. Indian Journal of Research 2013; 2(8): 125-128.

8. Sakarkar D, Deshmukh V. Ethnopharmacological Review of Traditional Medicinal Plants for Anticancer Activity.
International Journal of PharmTech Research 2011; 3(1): 298-308.

9. Kaur G, Kapoor A, Kaur G.

Ethnopharmacological Review of Traditional Herbal Plants for Anticancer Activity. World Journal of Pharmacy and Pharmaceutical Sciences 2015; 4(9): 244-264.

10. Zakaria M, Mohd MA. Traditional Malay Medicinal Plants: Institut Terjemahan Negara Malaysia Berhad.

11. Ahmad W, Zeenat F, Hasan A, et al. Mazu (Quercus infectoria, Oliv)-An Overview. Indian Journal of Unani Medicine 2011; 4(1):17-22.

12. Umachigi S, Jayaveera K, Kumar CA, Kumar G, Kumar DK. Studies on Wound Healing Properties of Quercus Infectoria. Tropical Journal of Pharmaceutical Research 2008; 7 (1):913-919.

13. Aroonrerk N, Kamkaen N. Anti-inflammatory activity of Quercus infectoria, Glycyrrhiza uralensis, Kaempferia galanga and Coptis chinensis, the main components of Thai herbal remedies for aphthous ulcer. Journal of Health Research 2009; 23(1):17-22.

14. Shahrzad S, Kazumasa A, Antje W, Akio K, Irmgard B. Pharmacokinetics of Gallic Acid and its Relative Bioavailability from Tea in Healthy Humans. The Journal of Nutrition 2001; 131(4): 1207-1210.

15. Hasmah A, Nurazila Z, Chow CY, Rina R, Rafiquzzaman M. Cytotoxic effects of Quercus infectoria extracts towards cervical (Hela) and Ovarian (Caov-3) cancer cell lines. Health and the Environment Journal 2010; 1(2):17-23.

16. Choudhury A, Das S, Kar M. A review on novelty and potentiality of vaginal drug delivery. International Journal of PharmTech Research 2011; 3(2):1033-44.

17. Zong $S$, Wang $X$, Yang $Y$, et al. The Use of Cisplatin-Loaded Mucoadhesive Nanofibers for Local Chemotherapy of Cervical Cancers in Mice. European Journal of Pharmaceutics and Biopharmaceutics 2015; 93:127-135.

18. Hapidin $\mathrm{H}$, Rozelan D, Abdullah H, Hanaffi WN, Soelaiman IN. Quercus infectoria gall extract enhanced the proliferation and activity of human fetal osteoblast cell line (hFOB 1.19). The Malaysian journal of medical sciences: MJMS. 2015 Jan; 22(1):12.

19. Paithankar V. Formulation and Evaluation of Herbal Cosmetic Preparation Using Safed Musli. International Journal of PharmTech 
Research 2010; 2(4): 2261-2264.

20. Fotakis G, Timbrell JA. In vitro cytotoxicity assays: comparison of LDH, neutral red, MTT and protein assay in hepatoma cell lines following exposure to cadmium chloride. Toxicology letters 2006 Jan 5; 160(2):171-7.

21. Mosmann T. Rapid Colorimetric Assay for Cellular Growth and Survival: Application to Proliferation and Cytotoxicity Assays. Journal of Immunological Methods 1983; 65(1):55-63.

22. Sajjadi SE, Ghanadian M, Haghighi $M$, Mouhebat L. Cytotoxic Effect of Cousinia Verbascifolia Bunge Against OVCAR-3 and HT29 Cancer Cells. Journal of HerbMed Pharmacology 2015; 4(1):15-19.

23. Debata PR, Castellanos MR, Fata JE, et al. A novel curcumin-based vaginal cream Vacurin selectively eliminates apposed human cervical cancer cells. Gynecologic oncology 2013 Apr 30; 129(1):145-53.

24. Gendron RM, Mansell P. Methods for Successful Intra-Vaginal Dosing in Rats, Charles River Laboratories Preclinical Services Montreal, Quebec, Canada. 2014.

25. Nur Syukriah A, Liza M, Harisun Y, Fadzillah A. Effect of Solvent Extraction on Antioxidant and Antibacterial Activities from Quercus Infectoria (Manjakani). International Food Research Journal 2014; 21(3):1031-1037.

26. Nurazila, Z. Cell Death Mechanism of Cervical Cancer (HeLa) Cells Treated with Quercus Infectoria Galls Aqueous Extract. (Dissertation). Master Degree, University Science Malaysia, 2015.

27. Okamoto Y, Tobe T, Ueda K, Kojima N. Anticancer Effect of Platinum (IV) Complex Against Cisplatin-Resistant Human Ovarian Cancer. Cancer Research 2015; 75(15): 44854485.

28. Uehara T, Mitsuhashi A, Tsuruoka N, Shozu M. Metformin Potentiates The Anticancer Effects of Cisplatin Under Normoxic Conditions In Vitro. Oncology Reports 2015; 33(2):744-750.

29. Zazali KE, Abdullah H, Noor Jamil N. Methanol Extract of Oroxylum Indicum Leaves Induces G1/S Cell Cycle Arrest in Hela Cells Via P53. Mediated Pathway. International Journal of Medicinal Plant Research 2013; 2(7):225-237.

30. Pabla N, Dong Z. Cisplatin Nephrotoxicity: Mechanisms and Renoprotective Strategies. Kidney International 2008; 73(9):994-1007.

31. Raybould R, Fiander A, Hibbitts S. Human
Papillomavirus Integration and its Role in Cervical Malignant Progression. The Open Clinical Cancer Journal 2011; 5:1-7.

32. Ismail NE, Samad MA, Effendi TJ, Hasan MH. Cytotoxicity studies of aqueous extracts of Curcuma longa and Quercus infectoria. InScience and Social Research (CSSR), International Conference on 2010, IEEE, 2010Dec 5: 746-751.

33. Iminjan M, Amat N, Li XH, et al. Investigation into the toxicity of traditional Uyghur medicine Quercus Infectoria galls water extract. PloS one 2014 Mar 7; 9(3):e90756.

34. Kaur R, Kapoor K, Kaur H. Plants as a Source of Anticancer Agents. Journal of Natural Product and Plant Resources 2011; 1(1):119124.

35. Garhwal S. Medicinal plants as a source of antioxidants. Research Journal of Phytochemistry 2010; 4(4):213-24.

36. Kaur G, Athar M, Alam MS. Quercus infectoria galls possess antioxidant activity and abrogates oxidative stress-induced functional alterations in murine macrophages. ChemicoBiological Interactions 2008 Feb 15; 171 (3):272-82 .

37. Rohana S, Vimala S, Rashih AA, Ilham AM. Skin Whitening and Antioxidant Properties of Quercus Infectoria Galls. Proceedings from Proceedings of the Seminar on Medicinal Plant. Forest Research Institute Malaysia (FRIM), Selangor, 2004.

38. Azwanida NN. A Review on the Extraction Methods Use in Medicinal Plants, Principle, Strength and Limitation. Medicinal Aromatic Plants 2015; 4 (3): 2-6 doi:10.4172/21670412.1000196

39. Ruela ALM, Perissinato AG, Lino MES, Mudrik PS, Pereira GR. Evaluation of skin absorption of drugs from topical and transdermal formulations. Brazilian Journal of Pharmaceutical Sciences 2016; 52 (3): 527-544 doi.org/10.1590/S1984-82502016000300018 